Title no. 110-S22

\title{
Experimental Investigation on Reinforced Ultra-High- Performance Fiber-Reinforced Concrete Composite Beams Subjected to Combined Bending and Shear
}

\author{
by Talayeh Noshiravani and Eugen Brühwiler
}

\begin{abstract}
An experimental study on a series of composite beams combining a $250 \mathrm{~mm}$ (9.84 in.) deep reinforced concrete ( $R C)$ element and a $50 \mathrm{~mm}$ (1.97 in.) thick reinforced ultra-high-performance fiberreinforced concrete ( $R$-UHPFRC) element is presented. The specimens are tested in a cantilever-beam setup with the R-UHPFRC element acting as an additional tensile reinforcement. The test parameters include the span length and the ratio and type of the steel reinforcing bars, including stirrups. Most of the beams fail in flexure at a force that is 2.0 to 2.8 times higher than the resistance of the reference RC beams. The medium-span cantilevers with a low stirrup content failure along a flexure-shear crack. Nearinterface concrete cracking softens the bond between the elements and enhances the member deformation capacity. The R-UHPFRC element contributes significantly to the shear resistance.
\end{abstract}

Keywords: composite beams; debonding; deformation capacity; flexureshear resistance; ultra-high-performance fiber-reinforced concrete.

\section{INTRODUCTION}

The addition of a thin overlay of ultra-high-performance fiber-reinforced concrete (UHPFRC) to reinforced concrete (RC) members is an emerging technique for durable design, protection, and strengthening of concrete structures. ${ }^{1}$

UHPFRC belongs to the family of ultra-high-strength cementitious composites. Due to its compact matrix, the material is quasi-impermeable. The homogenous distribution of fine and discontinuous steel fibers in the matrix provides the material's notably high tensile resistance and ductility. As illustrated in Fig. 1(a), the UHPFRC behavior in direct tension is manifested in three phases of elastic strain hardening due to multiple microcracking and strain softening due to localization of deformations at an individual macrocrack. The member geometry, presence of reinforcing bars, and UHPFRC casting procedure have a strong influence on the fiber orientation and, thus, the tensile behavior.

A thin layer of UHPFRC reinforced with small-diameter steel reinforcing bars can be used as a protective flexural reinforcement on RC members (Fig. 1(b)). Cast-in-place or glued reinforced UHPFRC (R-UHPFRC) layers on flexural $\mathrm{RC}$ elements create composite members with an enhanced load-bearing behavior. ${ }^{2,3}$ From hereafter, R-UHPFRC-RC composite members are referred to as RU-RC members. For floor slabs and bridge decks, Habel et al. ${ }^{3}$ recommend an R-UHPFRC-to-RC height ratio between 10 and $20 \%$ with an R-UHPFRC thickness between 30 and $100 \mathrm{~mm}$ (1.81 and 3.94 in.). This design recommendation ensures the optimum interaction between the two elements and their contribution to the member resistance. It also allows for an economic use of UHPFRC.

Closely spaced steel reinforcing bars in the R-UHPFRC layer provide in-plane continuity that ensures the layer's
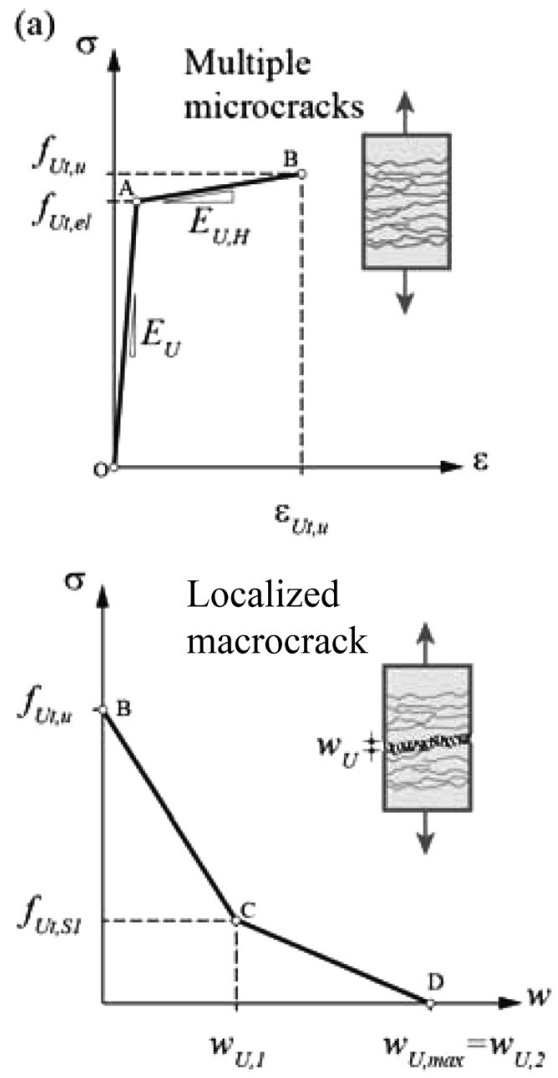

(b)

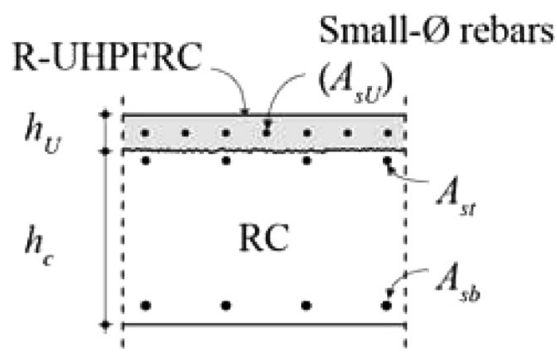

Fig. 1-(a) Constitutive law of UHPFRC in tension ${ }^{3}$; and (b) cross section of $R U-R C$ slab strip cross section.

ACI Structural Journal, V. 110, No. 2, March-April 2013

MS No. S-2011-115.R2 received March 5, 2012, and reviewed under Institute publication policies. Copyright (C) 2013, American Concrete Institute. All rights reserved, including the making of copies unless permission is obtained from the copyright proprietors. Pertinent discussion including author's closure, if any, will be published in the January-February 2014 ACI Structural Journal if the discussion is received by September 1, 2013 
Talayeh Noshiravani is an Engineer at Zilch + Müller Ingenieure, Munich, Germany. She received her BASc from the University of Waterloo, ON, Canada; her MASC from the University of Toronto, ON, Canada; and her PhD from the École Polytechnique Fédérale de Lausanne (EPFL), Lausanne, Switzerland. Her research interests include applications of ultra-high-performance fiber-reinforced concrete (UHPFRC) in structural design and strengthening projects, evaluation of load-bearing capacity of existing structures, and experimental investigations on the behavior of structures.

Eugen Brühwiler is a Professor of structural engineering and the Head of the Laboratory of Maintenance and Safety of Structures (MCS) at the EPFL. He received his civil engineering and doctoral degrees from the Swiss Federal Institutes of Technology in Zurich in 1983 and Lausanne in 1988. His research interests include UHPFRC for the rehabilitation of structures, reliability and safety of structures, remaining fatigue life and dynamic behavior of existing bridges, monitoring, and nondestructive testing methods.

\section{Table 1-Cantilever beam tests}

\begin{tabular}{|c|c|c|c|c|c|c|c|c|}
\hline Beam & $a, \mathrm{~mm}$ & $s, \mathrm{~mm}$ & ald & $\begin{array}{c}\rho_{v}, \\
\%\end{array}$ & $\begin{array}{c}\omega_{s t}, \\
\%\end{array}$ & $\begin{array}{c}\omega_{U}, \\
\%\end{array}$ & $\begin{array}{c}\omega_{s U}, \\
\%\end{array}$ & $\begin{array}{c}A_{s U} \text { steel } \\
\text { grade }^{*}\end{array}$ \\
\hline L0 & \multirow{4}{*}{1000} & 200 & 4.2 & 0.34 & 8.1 & 0 & 0 & - \\
\hline L1 & & \multirow{2}{*}{400} & 4.0 & 0.17 & 8.1 & 3.9 & 0 & - \\
\hline L2 & & & 3.8 & 0.17 & 8.1 & 3.9 & 9.2 & Inox \\
\hline L3 & & 200 & 3.8 & 0.34 & 8.1 & 3.9 & 9.2 & Inox \\
\hline MNO & \multirow{11}{*}{800} & \multirow{3}{*}{200} & 3.4 & 0.34 & 8.1 & 0 & 0 & - \\
\hline MN1 & & & 3.1 & 0.34 & 8.1 & 3.9 & 6.7 & $11 \mathrm{MSn} 30$ \\
\hline MN2 & & & 3.1 & 0.34 & 8.1 & 3.9 & 9.1 & ETG88 \\
\hline MN3 & & 250 & 3.0 & 0.15 & 16.8 & 3.9 & 9.2 & Inox \\
\hline MW0 & & \multirow{7}{*}{400} & 3.4 & 0.17 & 8.1 & 0 & 0 & - \\
\hline MW1 & & & 3.2 & 0.17 & 8.1 & 3.9 & 0 & - \\
\hline MW2 & & & 3.1 & 0.17 & 8.1 & 3.9 & 6.7 & $11 \mathrm{MSn} 30$ \\
\hline MW3 & & & 3.1 & 0.17 & 8.1 & 3.9 & 6.9 & Inox \\
\hline MW4 & & & 3.1 & 0.17 & 8.1 & 3.9 & 7.3 & B500 B \\
\hline MW5 & & & 3.1 & 0.17 & 8.1 & 3.9 & 9.1 & ETG88 \\
\hline MW6 & & & 3.0 & 0.09 & 16.8 & 3.9 & 9.2 & Inox \\
\hline SN1 & \multirow{2}{*}{600} & 200 & 2.3 & 0.34 & 8.1 & 3.9 & 6.7 & $11 \mathrm{MSn} 30$ \\
\hline SW1 & & 400 & 2.3 & 0.17 & 8.1 & 3.9 & 6.7 & $11 \mathrm{MSn} 30$ \\
\hline
\end{tabular}

*Steel grade of $8 \mathrm{~mm}(0.3 \mathrm{in}$.) diameter reinforcing bars in R-UHPFRC.

Note: $1 \mathrm{~mm}=0.0394$ in

composite action with the RC element. ${ }^{3-5}$ Thus, RU-RC members can be designed without any mechanical device or stirrups connecting the two elements. Research on the flexural resistance and load-bearing behavior of RU-RC beams and slab strips has shown the monolithic behavior of the two elements up to the maximum bending resistance., ${ }^{2,3,5}$ Thus, RU-RC members with bonded reinforcement can be designed based on the plane-sections hypothesis. Oesterlee ${ }^{5}$ recommends using high-strength ribbed or smooth reinforcing bars in RU-RC members to provide a high flexural strength or a high rotation capacity, respectively.

An inadequate shear resistance may determine the member response of RC beams or slabs that are strengthened with additional flexural reinforcement only. ${ }^{6,7}$ There is currently insufficient test data on the shear behavior of RU-RC members. A conservative approach is to assume that only the RC element in the composite member carries the shear forces. This is particularly problematic when the RC element's shear resistance and rotation capacity limit the flexural strengthening of RU-RC members without the addition of any shear reinforcement.
To improve the understanding of the response of RU-RC members and their shear strength, an experimental program involving RU-RC beams was carried out. ${ }^{8}$ The beams were subjected to quasi-static loading. The test parameters included shear span-depth ratio $(a / d)$, the amount of transverse and longitudinal reinforcement, and the strength and bond condition of the R-UHPFRC reinforcing bars. The results are compared to the failure criterion of the Critical Shear Crack Theory (CSCT) for beams. ${ }^{9}$

\section{RESEARCH SIGNIFICANCE}

Changes in the service conditions and the state of existing structures may necessitate strengthening interventions. Flexural strengthening of existing slabs and bridge decks may require additional shear reinforcement, thus increasing the intervention costs. RU-RC members offer a cost-effective, durable, and low-impact solution in strengthening projects. RU-RC composite members shall also be used in new structures. Can an R-UHPFRC layer contribute to member resistance and prevent the need for shear strengthening? This research aims to provide a better understanding of the flexure-shear behavior of RU-RC beams and the contributions of R-UHPFRC reinforcement to the member resistance.

\section{EXPERIMENTAL INVESTIGATION}

\section{Test specimens and parameters}

To predict the resistance of RU-RC members, it is important to consider the shear resistance mechanisms in the $\mathrm{RC}$ element and the influence of the R-UHPFRC layer on these mechanisms. Previous research has shown the influence of the $a / d$, the ratio of the longitudinal reinforcement $\rho_{l}$, the bond condition of the reinforcing bars, the transverse reinforcement ratio $\rho_{v}$, and the stirrup spacing $s$ on the shear strength of RC beams. ${ }^{6,10}$ These parameters influence the mechanisms of shear resistance and the flow of stresses carried by the concrete and steel components (Appendixes A and $\left.\mathrm{B}^{*}\right) .^{6-21}$ The aforementioned parameters are used in the experimental program exploring the structural response of RU-RC members.

The experimental program involves 12 RU-RC beams, two UHPFRC-RC composite beams, and three reference RC beams. Equations (1) to (3) calculate the effective depth of the composite section $d, \rho_{v}$, and the mechanical reinforcement ratios $\omega_{i}$. In Eq. (1) and (3), $i$ stands for each tensile longitudinal reinforcement-namely, UHPFRC or tensile steel reinforcing bars in the RC or R-UHPFRC sections (subscripts $U$, st, or $s U$, respectively); $d_{i}$ is the distance between the neutral axis of each reinforcement and the extreme compressive fiber; and $f_{i}$ is the reinforcement elastic limit strength.

$$
\begin{gathered}
d=\sum\left(d_{i} A_{i} f_{i}\right) / \sum\left(A_{i} f_{i}\right) \\
\rho_{v}=A_{s v} / s / b \\
\omega_{i}=\left(A_{i} f_{i}\right) /\left(A_{c} f_{c}\right)
\end{gathered}
$$

"The Appendixes are available at www.concrete.org in PDF format as an addendum to the published paper. They are also available in hard copy from ACI headquarters for a fee equal to the cost of reproduction plus handling at the time of the request. 
The test parameters for each beam are listed in Table 1. The beam names distinguish between the beams with a long (L), medium (M), or short (S) cantilever span. The specimens with a medium and short span are further differentiated according to their narrow (N) or wide (W) stirrup spacing. The names of the reference RC beams end with 0 . The composite beams are numbered according to the increasing reinforcement content. With the exception of Beams MN3 and MW6, all other specimens were undamaged end segments cut from longer beams that were previously tested in four-point bending by Oesterlee ${ }^{5}$ and Noshiravani. ${ }^{8}$

The specimen cross sections and reinforcement detailing are shown in Fig. 2(a). All composite specimens have a $250 \mathrm{~mm}$ (9.84 in.) deep RC element covered with a $50 \mathrm{~mm}$ (1.97 in.) thick layer of UHPFRC. The reference RC beams have a depth of $265 \mathrm{~mm}$ (10.43 in.). The widths of all beams are $150 \mathrm{~mm}$ (5.90 in.). The RC elements in all of the beams, except Beams MN3 and MW6, have the same reinforcement detailing. Beams MN3 and MW6 have a higher ratio of longitudinal reinforcement but a lower $\rho_{v}$ than the rest of the beams. The R-UHPFRC layers have three or four reinforcing bars with a diameter of $8 \mathrm{~mm}(0.32 \mathrm{in}$.). The longitudinal reinforcing bars are anchored beyond the supports with welded cross reinforcing bars.

\section{Material properties}

Commercial ready mixed concrete (C30/37) with an aggregate size of $16 \mathrm{~mm}$ (0.63 in.) was used to cast the $\mathrm{RC}$ elements. The average values of the concrete properties in Table 2 are based on the standardized tests during the beam tests for concrete ages between 126 and 246 days.

The specimens were cast with a UHPFRC mixture named HIFCOM 13 developed at the École Polytechnique Fédérale de Lausanne. ${ }^{5}$ The average UHPFRC tensile properties in Table 2 are from direct tension tests carried out by Oesterlee. ${ }^{5}$ The mixture design and the results of direct tensile tests on dogbone specimens are provided in Appendix B. Furthermore, the UHPFRC's average cylinder compressive strength $f_{U c}$ is $160 \mathrm{MPa}(23.2 \mathrm{ksi})$ for UHPFRC of ages of 90 and 210 days. The compressive behavior of UHPFRC up to this strength is almost linear. The tested UHPFRC modulus of rupture $f_{U r}$ was $51.0 \mathrm{MPa}(7.40 \mathrm{ksi})$ for the same UHPFRC age.

The steel properties in Table 2 are the average values from the standardized tensile tests on three random samples. The tensile response of the tested reinforcing bars is provided in Appendix C. The tested bond strengths of the ribbed and smooth reinforcing bars are 44 and $5 \mathrm{MPa}$ (6.38 and $0.725 \mathrm{ksi})$ at a slip of 0.80 and $0.01 \mathrm{~mm}(0.031$ and 0.0004 in.), respectively. ${ }^{5}$

\section{Test setup and procedure}

The cantilever-beam test setup is illustrated in Fig. 2(b). The fixed end is provided by an end pin support, attached to an isolated steel frame, and an intermediate roller support, placed on a massive concrete block. The external vertical prestressing between the supports prevents a shear failure outside the cantilever span. The tests are displacementcontrolled. The displacement is applied with a hydraulic jack attached to a second isolated steel frame.

The following parameters were measured automatically during each test: forces, beam deflections, support displacements, and the deformations across the concrete interface zone and along the UHPFRC layer and the steel reinforcing (a) Cross sections

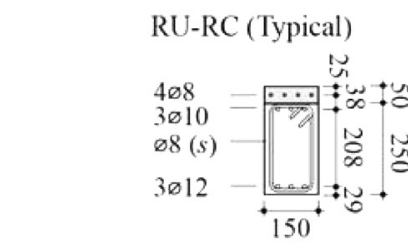

MW3

MN3/MW6
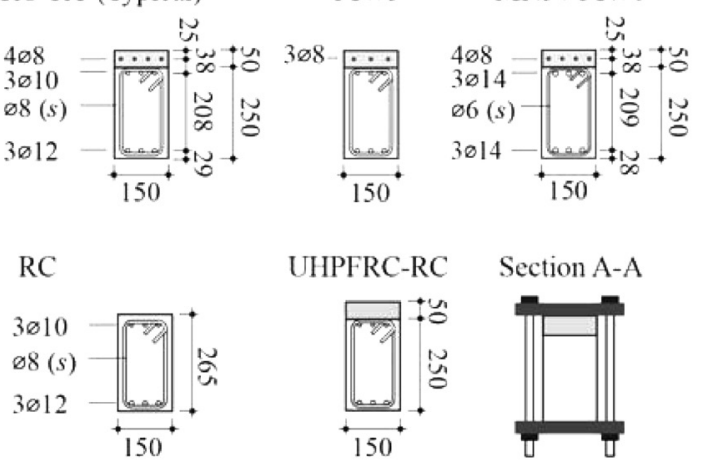

(b) Test setup

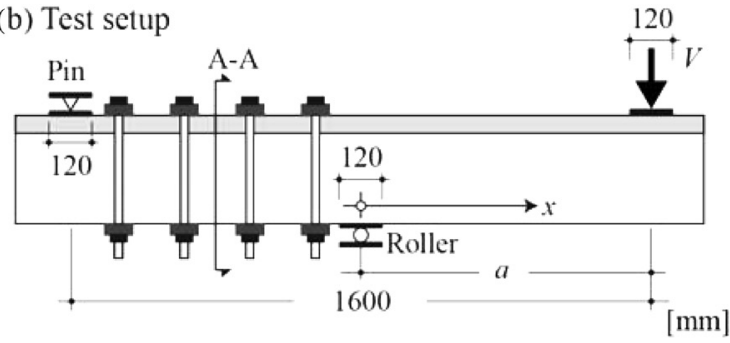

Fig. 2-Specimens and test setup. (Note: $1 \mathrm{~mm}=0.0394 \mathrm{in}$.)

Table 2-Mean values of tested material properties ${ }^{5}$

\begin{tabular}{|c|c|c|c|c|c|c|c|}
\hline \multicolumn{8}{|c|}{ Concrete } \\
\hline \multicolumn{2}{|l|}{$E_{c}, \mathrm{GPa}$} & \multicolumn{2}{|c|}{$f_{c, \text { cube }}, \mathrm{MPa}$} & \multicolumn{2}{|c|}{$f_{c}, \mathrm{MPa}$} & \multicolumn{2}{|c|}{$f_{c t}, \mathrm{MPa}$} \\
\hline \multicolumn{2}{|l|}{29.9} & \multicolumn{2}{|c|}{47.4} & \multicolumn{2}{|c|}{41.6} & \multicolumn{2}{|c|}{3.80} \\
\hline \multicolumn{8}{|c|}{ UHPFRC } \\
\hline \multicolumn{2}{|c|}{ Elastic } & \multicolumn{3}{|c|}{ Strain hardening } & \multicolumn{3}{|c|}{ Strain softening } \\
\hline$E_{U}, \mathrm{GPa}$ & $f_{U t, e l}, \mathrm{MPa}$ & $\varepsilon_{U t, u}$ & $f_{U t, u}$ & $\mathrm{MPa}$ & $w_{U}, \mathrm{~mm}$ & & ${ }_{t, S}, \mathrm{MPa}$ \\
\hline \multirow{2}{*}{48.8} & \multirow{2}{*}{10.2} & \multirow{2}{*}{0.003} & \multirow{2}{*}{\multicolumn{2}{|c|}{12.5}} & 3.0 & & 4.0 \\
\hline & & & & & 6.5 & & 0 \\
\hline \multicolumn{8}{|c|}{ Steel } \\
\hline Steel grade & $E_{s}, \mathrm{GPa}$ & $\phi, \mathrm{mm}$ & $\begin{array}{c}f_{s y}, \\
\mathrm{MPa}\end{array}$ & $\varepsilon_{s u}, \%$ & $\begin{array}{l}f_{s u}, \\
\mathrm{MPa}\end{array}$ & $f_{s u} / f_{s y}$ & Surface \\
\hline- & \multirow{8}{*}{210} & 6 & 626 & 3.70 & 655 & 1.05 & Ribbed \\
\hline B500 B & & $8^{*}$ & 516 & 4.90 & 589 & 1.14 & Ribbed \\
\hline $11 \mathrm{MSn} 30$ & & $8^{\dagger}$ & 566 & 5.20 & 595 & 1.05 & Smooth \\
\hline Inox & & $8^{\dagger}$ & 710 & 2.20 & 906 & 1.27 & Ribbed \\
\hline ETG88 & & $8^{\dagger}$ & 703 & 7.70 & 902 & 1.28 & Smooth \\
\hline B500 B & & 10 & 594 & 4.30 & 653 & 1.10 & Ribbed \\
\hline B500 B & & 12 & 571 & 5.00 & 640 & 1.12 & Ribbed \\
\hline B500 B & & 14 & $565^{\ddagger}$ & 9.79 & 663 & 1.17 & Ribbed \\
\hline
\end{tabular}

${ }^{*}$ Stirrups and R-UHPFRC reinforcing bars.

$\mathrm{R}$-UHPFRC reinforcing bars only.

*Yield plateau ends at strain of $2 \%$.

Notes: $1 \mathrm{GPa}=1000 \mathrm{MPa}=145.0 \mathrm{ksi} ; 1 \mathrm{~mm}=0.0394$ in.

bars. Furthermore, beam deformations and crack openings were measured manually at chosen stages of displacement.

EXPERIMENTAL RESULTS AND DISCUSSION Observed member response and failure modes

Figures 3 and 4 illustrate the force-deflection responses and the fully developed crack patterns of the beams at the 
(a)
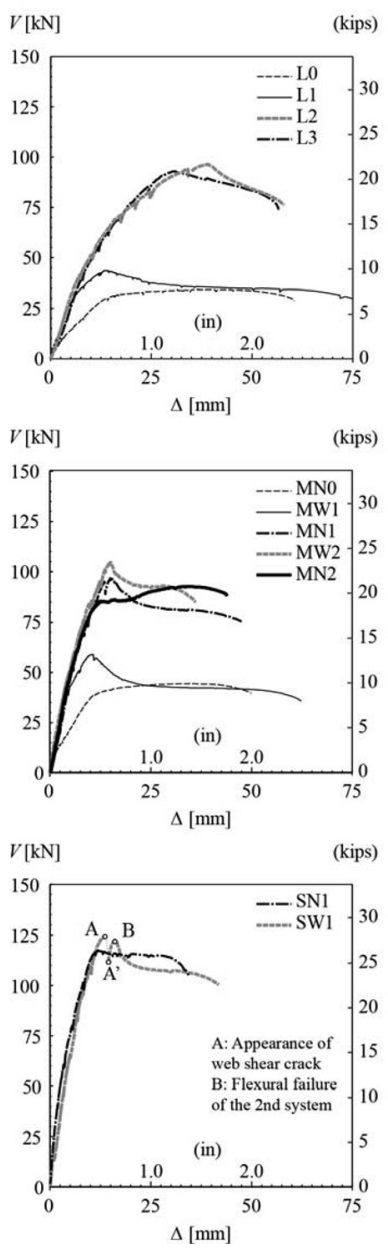

$V[\mathrm{kN}] \quad$ (kips)

(b) $\nabla$
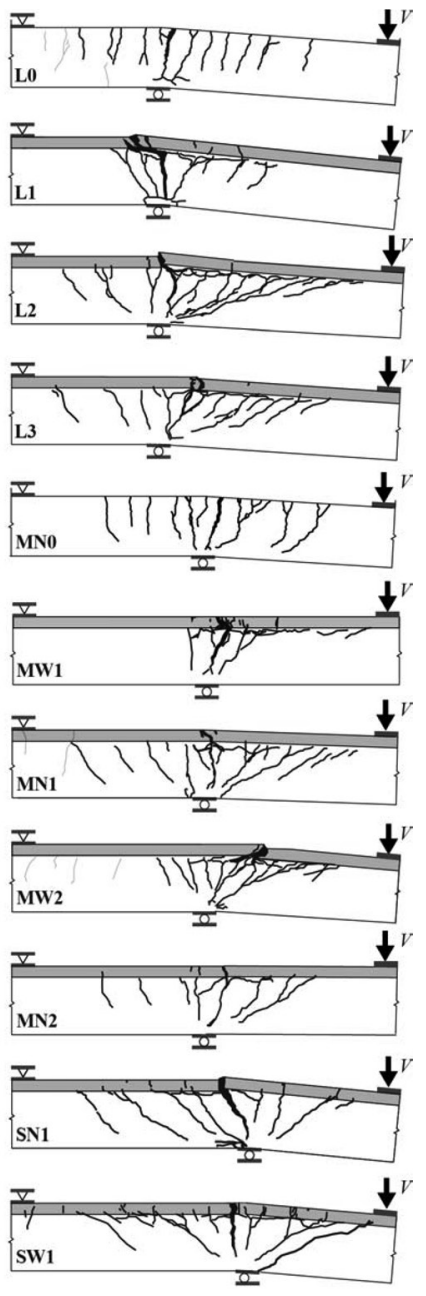

Fig. 3-Beams failing in flexure: (a)force-deflection responses; and (b) fully developed crack patterns at end of test.

end of the test. The variable $\Delta$ is the measured beam deflection at the jack with respect to the strong floor. The beams are divided into two groups according to their failure along a flexural or a flexure-shear collapse crack that is used to define the failure mode. The plots show the beam response either up to the first rupture of the tensile reinforcing bars or up to the maximum jack displacement. The fine dotted lines interrupting the continuity of the plots indicate the sudden drops of resistance, during which no measurements could be taken. The flexural failure of Beam SW1 follows the full development of a web-shear crack in the RC element. As illustrated in Fig. 4(a), the rotation of the RU-RC beams at flexure-shear failure is comparable to that of their reference RC beam.

The crack patterns in the figures were only traced on one side of the beam. Nevertheless, the patterns were very similar on the two vertical faces of the beams. The crack outline on top of the UHPFRC across the width of the member only varied slightly due to the heterogeneity of the material.

Figure 4(c) shows the crack pattern and manual crack width measurements at the last displacement stage before the ultimate resistance of the beams. In this figure, the jack force is given with respect to the ultimate force $V_{u}$. The web deformation in the composite beams with a flexure-shear failure localize at one or two diagonal cracks (Fig. 4(c)). The beams rotate about the crack tip close to the roller support. (a)

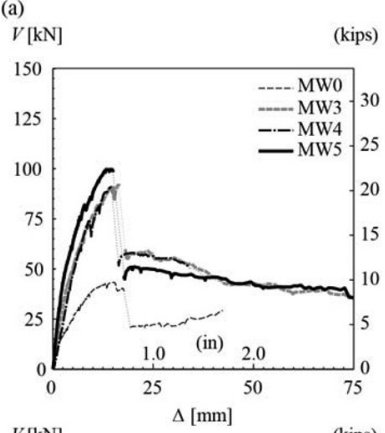

$V[\mathrm{kN}] \quad \Delta[\mathrm{mm}] \quad$ (kips)

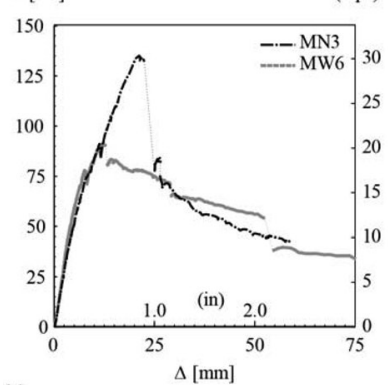

(c)
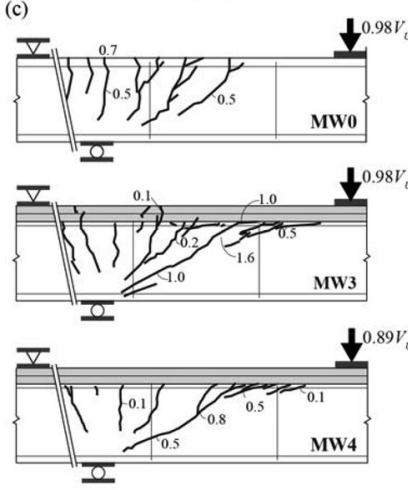

(b)
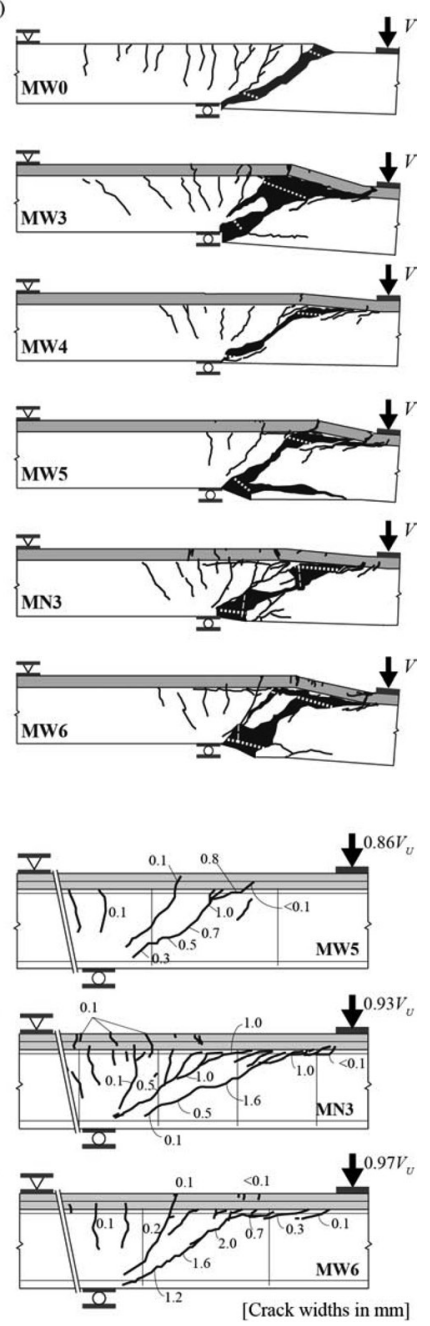

Fig. 4-Beams failing in flexure shear: (a) force-deflection responses; (b) fully developed crack patterns at end of test; and (c) crack widths. (Note: $0.4 \mathrm{~mm} \approx 1 / 64 \mathrm{in}$.)

Between approximately $80 \%$ and $90 \%$ of the respective ultimate resistance of each beam, the crack widths of the flexure-shear collapse cracks in the RU-RC beams are larger than their reference RC specimen. In Beams MW3 to MW6, the flexure-shear collapse crack crosses only one stirrup close to the crack tip at the support, whereas it crosses two stirrups in Beam MN3.

Table 3 summarizes the important results of each test at the ultimate resistance (that is, peak). It lists the measured angle of the collapse crack $\left(\theta_{c}\right)$, the maximum deflection of the cantilever span at peak $\left(\Delta_{u}\right)$, the calculated beam rotation $\left(\psi_{u}=\Delta_{u} / a\right)$, the peak force $V_{u}$, and the ultimate moment $\left(M_{u}=V_{u} a\right)$. The table also provides the moment resistance of the beams in the four-point bending tests $\left(M_{R, 4 p}\right)$ performed by Oesterlee. ${ }^{5}$ The latter value is corrected for the difference in the moment due to the dead load in each test setup. Table 3 also provides the ratios of $M_{u}$ to $M_{R, 4 p}$ and to $M_{R, R C}$. The latter is the bending moment resistance of the reference $\mathrm{RC}$ beams or the RC elements when there is no RC beam.

The $M_{u} / M_{R, 4 p}$ ratios greater than 1.0 can be explained by the larger variability of the UHPFRC tensile strength along the $1.8 \mathrm{~m}(5.91 \mathrm{ft})$ long region of constant moment in the fourpoint bending test setup instead of the support region in the 
Table 3-Summary of test results up to ultimate resistance

\begin{tabular}{|c|c|c|c|c|c|c|c|c|c|c|}
\hline Beam & ID $^{*}$ & Failure & $\theta_{c}$, degrees & $\Delta_{u}, \mathrm{~mm}$ & $V_{u}, \mathrm{kN}$ & $\psi_{u}, \mathrm{rad}$ & $M_{u}, \mathrm{kNm}$ & $M_{R, 4 p}, \mathrm{kNm}$ & $M_{u} / M_{R, 4 p}$ & $M_{u} / M_{R, R C}$ \\
\hline L1 & 04BRCU0 & Flexural & 90 & 13.8 & 43.4 & 0.014 & 43.4 & 34.8 & 1.25 & 1.25 \\
\hline L2 & 12B $4 \times 70 R 0$ & Flexural & 73 & 39.0 & 96.5 & 0.039 & 96.5 & 82.4 & 1.17 & 2.77 \\
\hline L3 & 12B $4 \times 70 R V$ & Flexural & 65 & 30.9 & 92.9 & 0.031 & 92.9 & 82.4 & 1.13 & 2.67 \\
\hline MN0 & 01BRCV & Flexural & 76 & 35.1 & 44.4 & 0.043 & 35.5 & 32.1 & 1.11 & 1.00 \\
\hline MN2 & 14B4x70SV & Flexural & 90 & 35.5 & 92.7 & 0.044 & 74.2 & 72.9 & 1.02 & 2.13 \\
\hline MN3 & 18S4x70RV & Flexure-shear & 22 & 21.0 & 134.7 & 0.026 & 107.8 & - & $1.00^{\dagger}$ & $1.96^{\ddagger}$ \\
\hline MW0 & 01BRC0 & Flexure-shear & 28 & 16.3 & 43.2 & 0.020 & 34.6 & 32.0 & 1.08 & 1.00 \\
\hline MW1 & 03BRCU0 & Flexural & 70 & 10.8 & 58.9 & 0.014 & 47.1 & 37.0 & 1.27 & 1.35 \\
\hline MW5 & 14B4x70S0 & Flexure-shear & 35 & 14.3 & 99.6 & 0.018 & 79.7 & 72.9 & 1.09 & 2.29 \\
\hline MW6 & 18S4x70R0 & Flexure-shear & 34 & 12.6 & 90.9 & 0.016 & 72.7 & - & $0.67^{\dagger}$ & $1.32^{\ddagger}$ \\
\hline SN1 & 10B4x50SV & Flexural & 90 & 12.4 & 115.0 & 0.021 & 69.0 & 63.7 & 1.08 & 1.98 \\
\hline SW1 & 09B4x50S0 & Flexural & $30 ; 90$ & $13.8 ; 16.1$ & $124.4 ; 122.0$ & $0.023 ; 0.027$ & $74.6 ; 73.2$ & 63.4 & 1.16 & $2.14 ; 2.10$ \\
\hline
\end{tabular}

"Beam ID used by Oesterlee. ${ }^{5}$

${ }^{\dagger}$ Ratio with respect to maximum bending resistance that is approximately resistance of MN3.

*Ratio with respect to maximum bending resistance of RC element that is $55.0 \mathrm{kNm}$ (40.4 kip-ft).

Notes: $1 \mathrm{~mm}=0.0394$ in.; $1 \mathrm{kN}=0.224$ kips; $1 \mathrm{kNm}=0.735 \mathrm{kip}-\mathrm{ft}$.

cantilever beams. The high $M_{u} / M_{R, R C}$ ratios in the last column indicate the effectiveness of the strengthening method.

Table 3 also indicates the failure mode of each beam: flexural (F) and flexure-shear (FS) failure. All of the RU-RC beams with long and short cantilever spans had a flexural failure. Among the medium-span beams, the beams with $\rho_{v}=0.34 \%$ and those with $\rho_{v}=0.17 \%$ and a $\omega_{s U}<6.9 \%$ also failed in flexure.

The rest of the medium-span beams with $\rho_{v} \leq 0.17 \%$ failed in a sudden manner due to the crushing of the concrete ahead of the diagonal flexure-shear collapse crack. Nevertheless, most of these beams reached their maximum bending resistance. The resistances of the RC beams indicate that the flexureshear failure of Beam MW0 occurred after the yielding of the longitudinal reinforcing bars. Similar to Beam MW0, the ultimate resistance of Beams MW3 to MW5 and MN3 coincide with the yielding of their R-UHPFRC reinforcing bars. This indicates that the failure of the composite beams along the flexure-shear collapse crack is close to its maximum bending resistance.

Beam MW6, with the same ratio of longitudinal reinforcement as MN3, fails at a force that is $67 \%$ of the resistance of MN3. Beam MW6 represents a clear case of a flexureshear failure and is used as a reference for classifying the failure mode of the other beams with an analogous pre-peak response. Moreover, it is important to note that the diagonal collapse cracks in the composite beams appear at an average force of $76.1 \mathrm{kN}$ (17.1 kips). This force is 1.7 times the ultimate resistance of the reference RC beam (MW0).

Increasing the mechanical ratio of the longitudinal reinforcement in the $\mathrm{RC}$ element is expected to reduce the member rotation capacity. Nevertheless, while the ultimate resistance of Beams MW3 to MW5 is 2.1 to 2.3 times higher than their reference beam MW0, their rotation at ultimate limit is between 90 and $100 \%$ of the latter.

Increasing the transverse reinforcement content by reducing the stirrup spacing has a positive influence on both the ultimate resistance and the rotation capacity of the beams. The stirrups crossing the flexure-shear collapse crack of Beam MN3 increase the ultimate resistance by 1.34 to 1.50 times that of the rest of the beams with a flexureshear failure. Its rotation at peak is 1.67 times higher than Beam MW6, with wider stirrup spacing.

In Fig. 3(a), the maximum bending resistance of the beams with ribbed or smooth reinforcing bars coincides with the yield limit of the reinforcing bars. The influence of the surface characteristics of the R-UHPFRC reinforcing bars depends on the properties of UHPFRC-namely, its tensile strength and strain softening behavior. Due to the high bond strength, the members with either ribbed or smooth reinforcing bars in the R-UHPFRC element have the same force-deflection response up to the softening of UHPFRC. For beams with ribbed reinforcing bars, the yield of the steel coincides with the start of the strain softening, while the yield of the smooth reinforcing bars may occur at the same time (for example, Beams MN1, MW2, and SW1) or well after the initiation of the UHPFRC softening (for example, Beams MN2 and SN1).

\section{Flexure-shear versus flexural failure}

The examples of Beams MW2 and MW4 are used to illustrate the response of a beam failing in flexure versus one that fails in flexure-shear. These beams are similar except for the surface characteristics and slightly different strengths of their R-UHPFRC reinforcing bars. For each beam, Fig. 5 shows: 1) the force-displacement response; 2) the deformed shape; 3) the sequential snapshots of the 
(a)

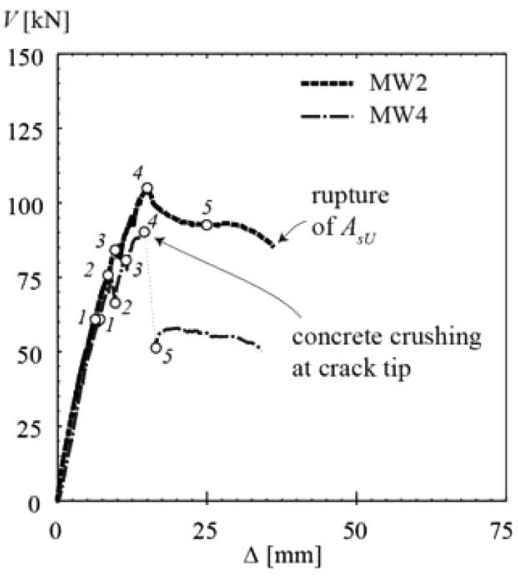

(c) Beam MW2
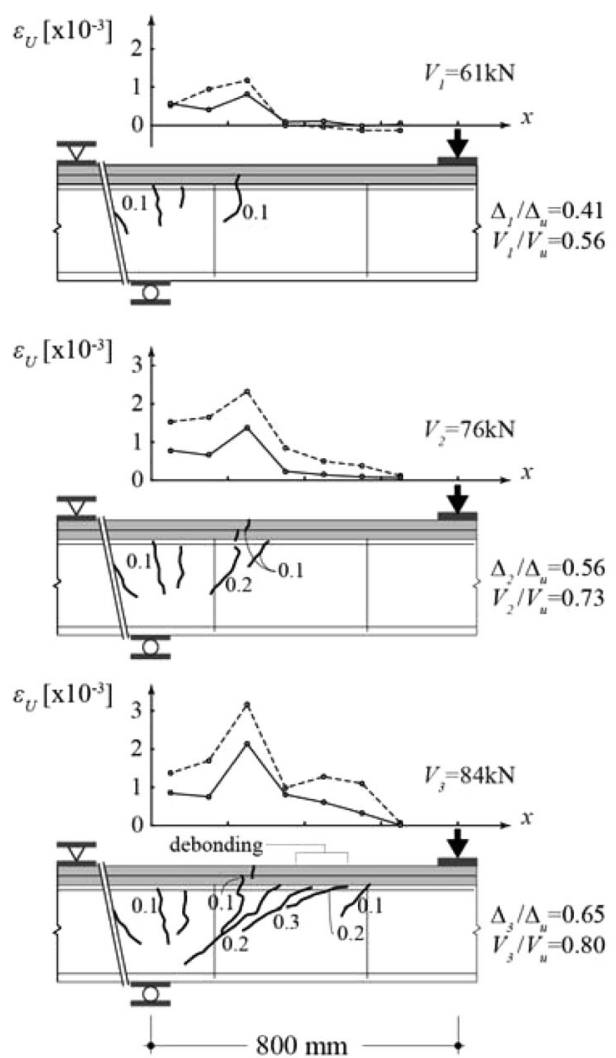

(b)
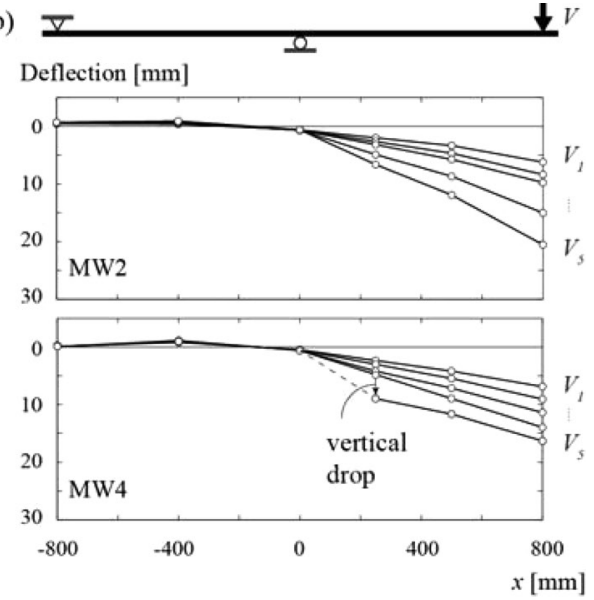

Beam MW4
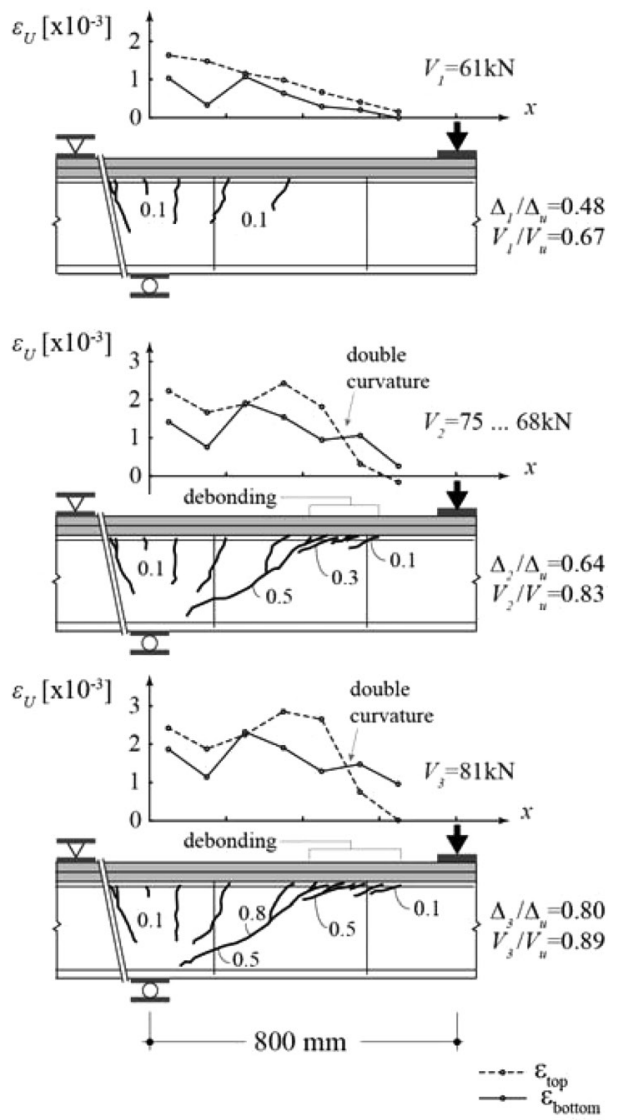

Fig. 5-Beam MW2 versus MW4: (a) force-deflection response; (b) deformed shape; and (c) crack widths and UHPFRC extreme-fiber strains. (Note: Crack widths are in units of $\mathrm{mm} ; 1 \mathrm{~mm}=0.039 \mathrm{in} . ; 0.4 \mathrm{~mm} \approx 1 / 64 \mathrm{in} . ; 1 \mathrm{kN}=0.224 \mathrm{kips}$.)

crack pattern with maximum measured crack widths; and 4) the corresponding plots of the manual strain measurements taken along the UHPFRC top and bottom fibers at indicated force levels.

Beam MW2, with smooth R-UHPFRC reinforcing bars, failed in flexure and MW4, with ribbed reinforcing bars, failed in flexure-shear. The bending moment resistance of Beam MW2 is $15 \%$ higher than the maximum resistance of Beam MW4. At this resistance, the difference of $\Delta_{u}$ of the beams is less than $5 \%$. The force-deflection responses of both beams up to a force of approximately $75 \mathrm{kN}$ (16.9 kips) are the same.

At $76 \mathrm{kN}$ (17.1 kips), Beam MW2 had only a few flexural cracks in the RC element and a UHPFRC macrocrack that began to form approximately $300 \mathrm{~mm}$ (11.8 in.) from the roller support. In contrast, in Beam MW4, a diagonal crack suddenly appeared, causing the force to drop by $10 \%$.

The flexure-shear crack in Beam MW4 developed down to the level of the compressive longitudinal reinforcing bars; with it, a series of inclined near-interface debonding cracks appeared. Extending $650 \mathrm{~mm}$ (25.6 in.) away from the roller, these cracks initiated as flexural cracks and rapidly rotated toward the collapse crack (Fig. 4(c)), reducing the beam stiffness. Meanwhile, the tensile strains along the bottom UHPFRC fiber increased. The double curvature of the R-UHPFRC element in Beam MW4 became obvious in the strain plot showing the increase of the bottom fiber strain measurements with respect to the top fiber strains. Beyond 
this force, the stiffness of MW4 reduced and the difference between the forces resisted by each beam increased from 10 to $15 \%$.

Up to $84 \mathrm{kN}$ (18.9 kips), more inclined flexural cracks developed in both beams. The measured crack widths in Beam MW2 were smaller than in MW4. At this force, the near-interface concrete in Beam MW2 also began to crack similarly to Beam MW4. The interface-zone cracks in the latter continued to grow as a series of smeared flat cracks. The strain diagrams show the strain hardening of the R-UHPFRC element along the cracked interface zone. The increased strains and force in the R-UHPFRC elements along the cracked interface zone are indicators of the change of the flow of stresses in the RC element.

Beyond $84 \mathrm{kN}$ (18.9 kips), the collapse crack in each beam opened. The angles of the flexural collapse crack in Beam MW2 and the flexure-shear crack in Beam MW4 were 50 and 30 degrees from the longitudinal axis, respectively. Beam MW2 failed due to the rupture of the smooth reinforcing bars in the R-UHPFRC element. In contrast, Beam MW4 failed due to the concrete crushing ahead of the tip of the flexure-shear collapse crack that separated the RC element into two segments, causing the vertical drop of the segment below the jack (Fig. 5(b)).

\section{Cracking behavior}

Collapse cracks-There are three main differences between the final crack pattern of the beams failing in flexure and those failing in flexure-shear: 1) the angle of the collapse crack in the RC element $\left.\left(\theta_{c}\right) ; 2\right)$ the location and angle of UHPFRC macrocracks; and 3) the intermediatecrack-induced debonding (ICD) zone.

The angles of the flexure collapse cracks in Fig. 3(b) are between 50 and 90 degrees from the longitudinal axis, whereas the angles of the flexure-shear collapse cracks in Fig. 4(b) vary from 22 to 35 degrees. The latter coincide with the principal compressive stress field in concrete along which the diagonal cracks grow.

Both the longitudinal and transverse reinforcement influence the crack widths and spacing in the composite beams. The UHPFRC element without reinforcing bars decreases the number of cracks and crack widths in the RC element. In composite RU-RC beams, flexural cracks are more smeared than those in the RC and the UHPFRC-RC beams. The crack patterns of Beam L2 $\left(\omega_{s U} \leq 9.2 \%\right)$ versus L1 with $\omega_{s U}=0 \%$ show that beams with a higher longitudinal reinforcement ratio in the R-UHPFRC element have more smeared flexural cracks with smaller openings.

In beams with wide stirrup spacing, the smeared cracking in the RC elements is interrupted by discrete flexure-shear cracks that compete with flexural cracks to become the collapse crack (Fig. 4(c)). In the members with $s=400 \mathrm{~mm}$ (15.7 in.), flexure-shear failure occurs at one single diagonal crack. Stirrups control the opening and development of diagonal cracks in the $\mathrm{RC}$ element. The influence of stirrups on the cracking behavior is illustrated in the difference between the crack patterns of Beam MN1 versus MW2 or Beam MN3 versus MW6.

The horizontal crack spacing in the beams with larger stirrup spacing is more irregular and generally smaller than the beams with smaller stirrup spacing-for example, Beam L2 versus L3. As the internal forces increase and secondary flexural cracks appear, the crack spacing in the $\mathrm{RC}$ element reduces. The crack spacing reduced in the near-

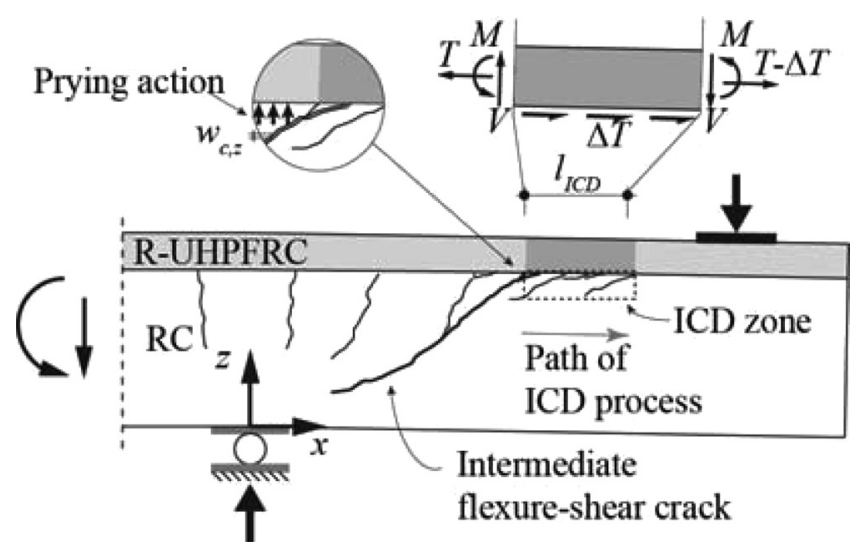

Fig. 6-Intermediate-crack-induced debonding (ICD).

interface concrete cracks that appeared subsequent to the formation of a long flexure-shear crack. The average of the measured spacing of these smeared cracks is approximately equal to or less than the thickness of the R-UHPFRC layer.

$I C D$-The stiffness of RU-RC composite members depends on the bond between the two elements. Indeed, in pure flexure, near-interface concrete cracks causing the debonding between the elements only begin once the UHPFRC strain softening occurs. ${ }^{3,5}$ The debonding is attributed to the deformation incompatibility between the two elements. The effect of this debonding on the behavior of RU-RC members is small enough to be neglected..$^{2,3}$ Nevertheless, the results of the tests presented herein show that, in the presence of bending and high shear stresses, the nearinterface concrete cracking prior to the maximum bending resistance and the UHPFRC strain softening influences the bond between the RC and its R-UHPFRC overlay, as observed in Beam MW4 (Fig. 5(c)).

As shown in Fig. 6, the widening of flexure-shear cracks induces vertical prying stresses at the crack mouth that provoke ICD of the two elements. ICD is classified as one of the failure modes of RC members with thin external flexural reinforcement, such as fiber-reinforced polymer (FRP) strips. ${ }^{22}$ Compared to its FRP or steel counterparts, however, an R-UHPFRC tensile reinforcement layer has a significantly higher bending stiffness and an out-of-plane resistance that can counteract the prying stresses.

Figure 6 illustrates the formation of the ICD zone as observed in the pre-peak response of the specimens presented herein. ICD is primarily manifested as closely spaced flexural cracks that are initially vertical but rapidly change direction toward the long diagonal cracks. The angles of the ICD cracks in the specimens range between 5 and 15 degrees from the longitudinal axis. Close to the maximum resistance, the angle of the smeared cracks decreases. The ICD may be seen as a volume of concrete softening with increasing deformation. The formation of the ICD zone is due to the geometrical compatibility between the R-UHPFRC and RC elements. By reducing the shear stresses transferred between the two elements, ICD decreases the member stiffness and allows for the formation of different stress transfer mechanisms.

The ICD zone approximately corresponds to the concrete layer between the R-UHPFRC-RC interface and the centerline of the RC tensile reinforcement. On the beam profile, the ICD zone begins at the mouth of diagonal cracks and extends horizontally with increasing deflection. The initiation of ICD cracks as flexural cracks suggests that the 

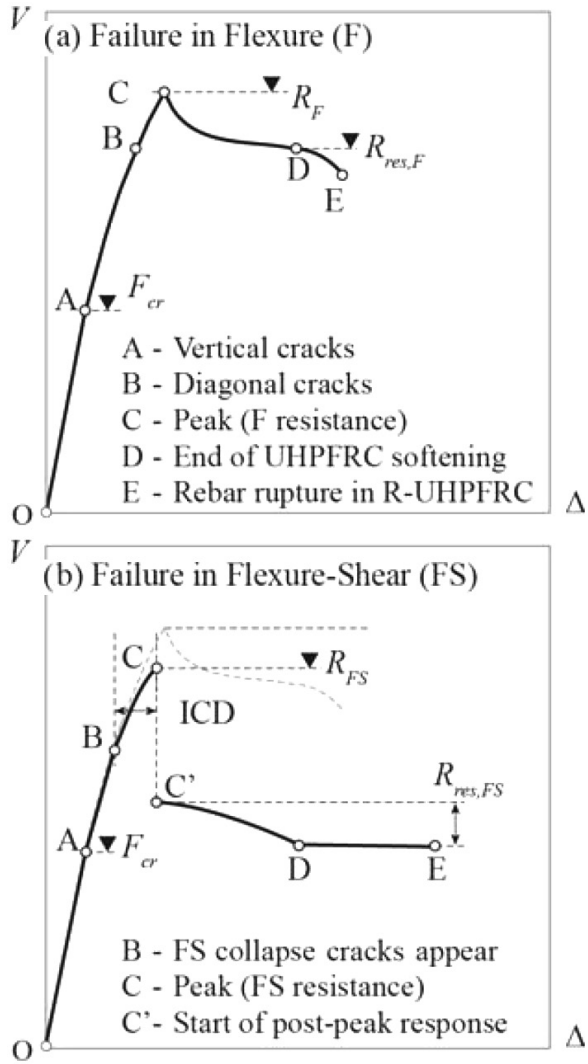

Fig. 7-Typical response of beams.

applied moment in the composite section at the forefront of the ICD zone is close to the cracking moment $M_{c r}$. The latter is defined as the moment causing the concrete stress at the interface fiber to exceed the tensile strength of concrete.

\section{Structural response of RU-RC composite beams}

General member response-Figure 7 illustrates the general structural responses of the beams with a flexural or flexure-shear failure and distinguishes between the various cracking states in the member. Irrespective of the failure mode, the general response of the beams can be divided into the pre- and post-peak regimes. In the pre-peak regime, the cracking behavior and the ICD determine the member rotation capacity. The maximum force and the collapse crack define the failure mode.

The failure of RU-RC members depends on the softening of the R-UHPFRC element at the mouth of a flexural or flexure-shear crack competing to become the collapse crack. Above flexural cracks, the UHPFRC is mainly in tension. The R-UHPFRC element at the mouth of flexure-shear cracks is subjected to combined tensile and bending stresses. Inclined flexural cracks induce both longitudinal and vertical tensile stresses in the UHPFRC, thus causing the macrocracks in UHPFRC to form at an angle less than 90 degrees from the longitudinal axis. The softening of the UHPFRC determines which crack becomes the collapse crack.

Contribution of $R$-UHPFRC element to member resistance-The maximum resistance of RU-RC members is defined by the member moment resistance. The contribution of the R-UHPFRC element to the member resistance strongly depends on the tensile properties of the UHPFRC.

The addition of tensile longitudinal reinforcement in the R-UHPFRC element increases the beams' bending resis- tance. In addition to resisting tensile stresses in the longitudinal (in-plane) direction, the UHPFRC layer can also resist vertical (out-of-plane) tensile stresses. Inclined flexural cracks can activate the tensile resistance of the layer in the vertical direction. The UHPFRC macrocrack along a diagonal crack appears at a distance of $d / \tan \theta_{c}$ away from the center of rotation. The vertical component of the tensile force in the UHPFRC away from the center of rotation can increase the member capacity. This increase in resistance can be seen by comparing the force-deflection response of Beam MW2 $\left(\theta_{c}=50\right.$ degrees $)$ with Beams MN1 and MN2 $\left(\theta_{c}=90\right.$ degrees $)$.

The test results further show the contribution of the $\mathrm{R}-\mathrm{UHPFRC}$ element to the member resistance. The response of Beam SW1 demonstrates that the out-of-plane resistance of UHPFRC prevents the failure of the composite member after the appearance of the diagonal web-shear crack in the RC element. Instead, following the rupture of the RC element, the R-UHPFRC layer transfers the out-of-plane stresses from the bearing plate under the jack to the intact trapezoidal segment of the RU-RC beam over the roller. This composite segment functions as a tapered beam that ultimately fails in flexure at approximately the same force level. Note that low shear resistance of concrete supporting the UHPFRC layer makes it impossible for the R-UHPFRC below the steel bearing plate to fail in shear. Indeed, the thickness of the layer and UHPFRC's resistance to vertical tensile stresses provide it a high enough shear resistance that the layer over the RC beam can only fail in bending.

In the case of Beams MW3 to MW6 and MN3, which failed in combined flexure and shear, the R-UHPFRC layer over the ICD zone bends in double curvature; thus, it carries a constant shear force. Member resistance decreases with widening of the diagonal cracks. The reduction is due to the decreased contribution of aggregate interlock along the diagonal cracks. Assuming that the contribution of the $\mathrm{RC}$ element is a function of beam rotation due to the diagonal crack opening, the additional resistance of the beams compared to their RC elements is due to the contribution of the R-UHPFRC element to the member shear resistance.

The contribution of the R-UHPFRC layer can be quantified in the case of Beams MW3 to MW5 with respect to the resistance of Beam MW0. At a given rotation, the resistance of the latter beam indicates the contributions of concrete and steel in the RC element. The difference between the resistance of each RU-RC beam and their reference $\mathrm{RC}$ beam is the contribution of the R-UHPFRC element in combined tension and bending.

Pre-peak rotation capacity-It is generally expected that additional tensile flexural reinforcement will reduce the rotation capacity of $\mathrm{RC}$ elements, whether failing in flexure or shear. This is not the case for all the beams in the test program described herein.

The ICD in the pre-peak regime increases the rotation capacity of the composite members. Among the beams failing in flexure, the influence of the ICD on the rotation capacity can be seen by comparing the behavior of the RU-RC beams with reference to that of the UHPFRC$\mathrm{RC}$ beams. As shown in Fig. 3(a), the rotations of Beams MN1 and MW2 at peak are 1.4 and 1.3 times the rotation of MW1, respectively, and the rotations of Beams L2 and L3 at peak are 2.8 and 2.2 times the rotation of $\mathrm{L} 1$, respectively.

In the case of the composite beams with a flexure-shear failure, the rotation of the RU-RC members at failure is 
between 90 and $100 \%$ of $\psi_{u}$ of their reference RC beam (MW0). In the latter beams, the ICD increases the member rotation and at the same time reduces the contribution of the R-UHPFRC element to the shear resistance.

By controlling the opening of the diagonal cracks, the stirrups indirectly control the opening of interface cracks and thus the progress of the ICD. The influence of the stirrups depends on the level of the shear force. For example, in the beams with the maximum shear span, the low stirrup content allowed opening of the diagonal cracks and the ICD; therefore, Beam L2 has a higher rotation capacity than L3. This is not the case for Beams MW2 and MN1 with $a=$ $800 \mathrm{~mm}$ (31.5 in.). The low content of well-spaced stirrups in Beam MN3 allowed the opening of the two flexure-shear cracks and a longer ICD zone, thus increasing the rotation capacity in comparison with Beam MW6.

Post-peak response-The post-peak regime of RU-RC members is distinguished by the significantly high residual resistance $R_{\text {res }}$ of the member. The response varies depending on the resistance of the UHPFRC with respect to its steel reinforcing bars, as well as the slip between the two in the softening phase of the UHPFRC.

The residual resistance in the post-peak regime is the maximum resistance after the end of the contribution of the UHPFRC section to the member resistance. While the postpeak resistance is not of interest in a resistance-based design of structural elements, it is advantageous in displacementbased design, where the plastic redistribution capacity of structural members is needed for the plastic rotation demands.

In members with a flexural failure, the post-peak response begins with the yielding of the steel reinforcing bars at the end of the strain-hardening phase of UHPFRC. This response is characterized by the gradual reduction of a beam's resistance $R$ down to a yield plateau. This definition does not apply if the yield plateau directly follows the ascending branch of the cracked-elastic structural response, such as the response of Beams SN1 or MN2. The behavior of these beams is due to the low strength of the UHPFRC with respect to its smooth reinforcing bars, the slip between the smooth reinforcing bars and the UHPFRC, and the yielding of the reinforcing bars as the UHPFRC softens.

The beams failing in combined flexure and shear have a sudden drop in resistance due to the development of the flexure-shear collapse crack into the compression zone over the roller and crushing of concrete. Up to the peak resistance, the UHPFRC is in strain hardening. In the post-peak regime, Beam MW6 maintains $87 \%$ of its resistance, whereas the other beams with less longitudinal reinforcement in their $\mathrm{RC}$ elements lose 40 to $54 \%$ of their resistance. While the force-deflection plots of Beams MW6 and MN3 (with a higher $\omega_{s t}$ ) gradually decrease, the plots of Beams MW3 to MW5 remain at an approximately constant resistance. The higher amount of reinforcement in the RC element implies that a higher portion of the force is carried by the beam action corresponding to the reinforcement in the RC element. The reduced strain in the R-UHPFRC element prior to the maximum resistance allows the layer to contribute more to the post-peak resistance of the member.

As the contribution of the UHPFRC to the post-peak resistance diminishes, the dowel and the membrane actions of the reinforcing bars continue to resist the downward movement of the jack. The resistance of these mechanisms can be determined using the models for RC members. ${ }^{21}$

\section{COMPARISON WITH EXISTING SHEAR MODELS FOR RC ELEMENTS}

The experimental results provided in this paper show that the RU-RC members have a higher ultimate resistance at a rotation level that is approximately equal to $\psi_{u}$ of their reference RC beam with a similar crack pattern. Moreover, the RU-RC beams have slightly larger crack widths. Given the proposed height ratio of the RC and R-UHPFRC elements by Habel et al., ${ }^{3}$ it is reasonable to assume that the shear stresses are mainly carried by the stress fields in the RC web. The web shear resistance depends on the degree of deformation, crack width, crack spacing, and size of the member.

The behavior of RU-RC beams with ICD cannot be evaluated based on the analysis of the monolithic composite section. ICD separates the components of the composite tension chord (that is, the RC reinforcing bars and the R-UHPFRC element) and changes the angle of the compressive stresses in the web. To account for the nonlinearity introduced by ICD, the response of RU-RC beams should be analyzed based on an integral approach focused on the member response. A comprehensive approach is to combine the equilibrium of stresses in a member with the geometrical compatibility and the material stress-strain relationships.

To compare the shear resistance of the composite beams to RC beams with equal bending resistance, the member response is compared to the failure criterion of the CSCT for beams without shear reinforcement. ${ }^{9}$ This theory takes an integral approach focusing directly on the member response. ${ }^{23}$ The CSCT uses the member rotation $\psi$ as an integral parameter to relate the shear strength to the opening of a discrete flexure-shear crack along which the web deformations concentrate. Equation (4) is the general CSCT expression for calculating the shear resistance $V_{C S C T}$ of beams, which explicitly accounts for aggregate interlock along the flexure-shear crack where shear failure happens. Variables $d_{g 0}$ and $d_{g}$ are the reference aggregate size of $16 \mathrm{~mm}(5 / 8 \mathrm{in}$.) and the actual concrete aggregate size. ${ }^{23}$ The constants $C_{1}$ and $C_{2}$ are factors related to the shear strength at which the critical flexure-shear crack appears and the decay of concrete contribution along the crack as it opens. For the failure criterion of beams developing plastic strains, $C_{1}$ and $C_{2}$ are 1/6 and 2 in the equation with SI units (MPa and $\mathrm{mm}$ ) or 2 and 2 in the equation with U.S. customary units (psi and in.), respectively. ${ }^{9}$

$$
\frac{V_{C S C T}(\psi)}{b d \sqrt{f_{c}}}=\frac{C_{1}}{1+C_{2} \frac{\psi d}{d_{g 0}+d_{g}}}
$$

Figure 8 shows the shear force-rotation plots of the composite beams with a flexure-shear failure versus the CSCT failure criterion calculated for the minimum and maximum values of $d$. The flexure-shear collapse cracks of all of the composite beams appear at a higher shear force than in the reference RC beam. The failure criterion for Beam MN3 is the cumulative sum of the CSCT criterion and the force in the stirrups crossing the diagonal cracks. As shown in Fig. 8(b), the stirrups crossing the crack begin to yield after the appearance of the second diagonal crack.

The resistance beyond the failure criteria is due to the contributions of the R-UHPFRC element. First, the distribution of stresses in the RU-RC element increases the shear force required for the development of the flexure-shear 


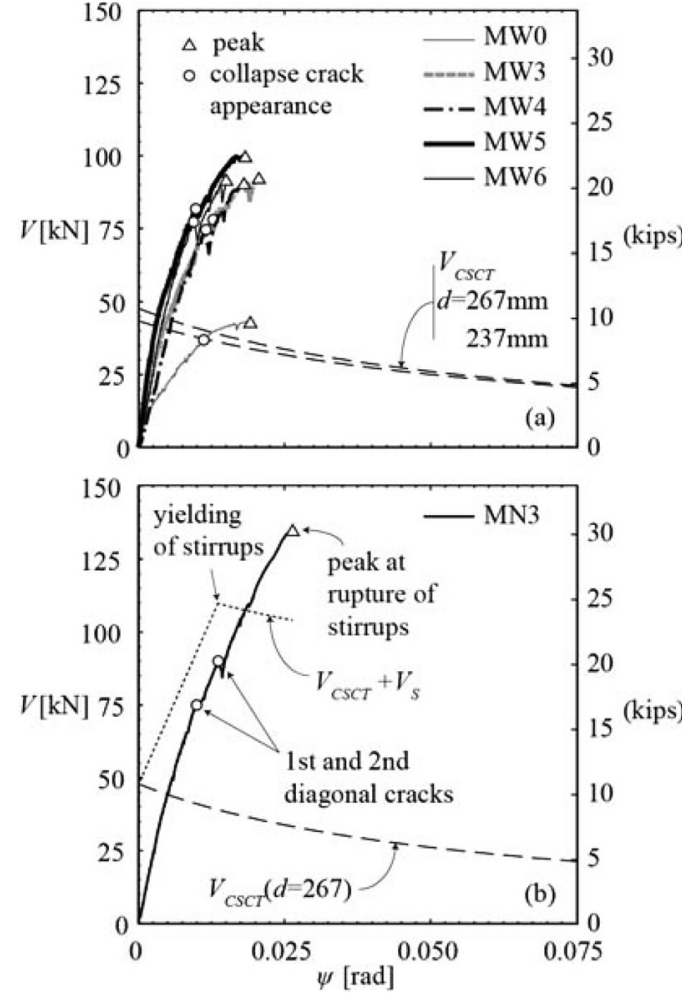

Fig. 8-Shear-rotation curves of $R U$-RC beams with flexureshear failure versus failure criterion according to CSCT. (Note: $1 \mathrm{~mm}=0.0394 \mathrm{in}$.)

crack. Second, the ICD reduces the angle of the compressive stresses carried by concrete in the forefront of the flexureshear crack. Third, the R-UHPFRC element carries part of the shear stresses in bending. In addition to these mechanisms, stirrups increase the member resistance and rotation capacity by carrying part of the stresses across the crack, as well as by controlling the opening of crack widths in the RC element and the ICD progress.

\section{CONCLUSIONS}

The following conclusions were reached:

1. RU-RC members have a significantly higher stiffness and ultimate resistance than their RC elements alone. The experiments show that the additional R-UHPFRC reinforcement can increase the ultimate resistance to up to 2.77 times that of the RC beam.

2. Both the in-plane and out-of-plane resistance of R-UHPFRC elements contribute to the member shear resistance. According to the models for RC beams, the specimens with the wide stirrup spacing should have failed in shear at a much lower resistance. The presence of the R-UHPFRC element allowed most of these specimens to reach their maximum bending moment at similar rotations as their reference RC beams. Hence, the addition of a tensile R-UHPFRC reinforcement can be used as an effective shear strengthening method.

3. The response of RU-RC members is strongly influenced by the formation of the ICD zone that softens the connection between the R-UHPFRC and RC elements, thus increasing the deformation capacity. As the ICD progresses, the plane section theory no longer holds for the composite member; however, it still remains valid for each individual element with bonded reinforcement. The ICD zone is more pronounced in members that carry higher shear stresses- that is, members with higher ratios of ribbed longitudinal reinforcement in the R-UHPFRC element.

4. The R-UHPFRC element contributes to the resistance of RU-RC members by three different means. First, the bending resistance of the R-UHPFRC elements allows the element to carry a part of the shear stresses introduced into the element by the prying action of RC segments formed by diagonal flexure-shear cracks. Second, the R-UHPFRC elements restrain the widening of a flexure-shear collapse crack in the RC element, thus improving the contribution of concrete to the shear resistance. Third, the ICD zone between the elements changes the stress fields in the member and reduces the intensity of the stresses that need to be carried across the flexure-shear collapse cracks.

5. For the RU-RC members with a flexure-shear failure, the deflection is between 80 and $90 \%$ of their matching RC specimen. This is especially important considering that the flexure-shear resistances of these RU-RC beams are 2.0 to 2.3 times that of the latter. The measured crack widths indicate that concrete carries only a minor part of the shear stresses. The increase in rotation capacity is due to the formation of the ICD zone.

6. Existing models for RC members cannot be used to determine the shear resistance and deformation capacity of RU-RC members. There is a need for a new analytical model that accounts for the contribution of the R-UHPFRC element to the member shear resistance.

\section{ACKNOWLEDGMENTS}

This study was funded by CTI Project 7787.1 EPRP-IW. The UHPFRC ingredients and the steel reinforcing bars were donated by HOLCIM and Swiss Steel. Their support is greatly appreciated.

\section{NOTATION}

Subscript notation follows standard notation

$A=$ area

$A_{s v} \quad=\quad$ stirrup area at stirrup spacing $s$

$a \quad=\quad$ shear $\operatorname{span}$

ald $=$ shear span-depth ratio

$b=$ beam width

$C=$ compression force; however, in CSCT equation, $C_{1}$ and $C_{2}$ designate constants

$d \quad=\quad$ effective depth

$d_{g}=$ concrete aggregate size

$d_{g 0} \quad=\quad$ reference aggregate size of $16 \mathrm{~mm}(5 / 8 \mathrm{in}$.

$d_{i}=$ depth of reinforcement $i$ with respect to extreme compressive concrete fiber

$d_{v} \quad=\quad$ vertical lever arm

$E_{c} \quad=\quad$ Young's modulus of elasticity of concrete

$E_{s} \quad=\quad$ Young's modulus of elasticity of steel

$E_{U} \quad=\quad$ Young's modulus of elasticity of UHPFRC

$E_{U, H}=$ stiffness of UHPFRC in strain-hardening phase

$E_{U, S}=$ stiffness of UHPFRC in strain-softening phase

$F \quad=$ force

$f_{c} \quad=\quad$ concrete cylinder compressive strength

$f_{c, \text { cube }}=$ concrete cube compressive strength

$f_{c t}$

$f_{i}$

$f_{i}$

$f_{s u}$

$f_{U c}$

$f_{U r}$

$f_{U t, e l}$

$f_{U t, S}$

$f_{U t, u}$

M

\section{$M_{c r}$}

$M_{R, R C}=$ moment resistance of reference $\mathrm{RC}$ beams or RC elements

$M_{R, 4 p}=$ moment resistance from four-point bending tests

$R^{\prime}=$ resistance

$R_{\text {res }}=$ residual resistance

$s \quad=\quad$ stirrup spacing 


$\begin{array}{lll}T & = & \text { tension force } \\ V & = & \text { shear force or force acting at end of cantilever span } \\ V_{C S C T} & = & \text { shear resistance based on CSCT } \\ w & = & \text { crack width } \\ x & = & \text { position or vector component along x-axis, with axis origin at } \\ & & \text { roller support } \\ \Delta & = & \text { beam displacement at jack with respect to strong floor } \\ \varepsilon & = & \text { strain } \\ \varepsilon_{s u} & = & \text { steel strain at ultimate strength } \\ \varepsilon_{s y} & = & \text { steel strain at yield stress } \\ \varepsilon_{U t, u} & = & \text { UHPFRC tensile strain at maximum tensile strength } \\ \theta_{c} & =\text { measured angle of collapse crack in concrete } \\ \rho_{l} & =\text { ratio of longitudinal reinforcement } \\ \rho_{v} & =\text { ratio of transverse reinforcement in RC element } \\ \sigma & =\text { stress } \\ \omega_{i} & =\text { mechanical reinforcement ratio of reinforcement } i \\ \psi & =\text { beam rotation } \\ \text { Subscripts } & \\ c & = & \text { concrete } \\ i & = & \text { steel or UHPFRC reinforcement } \\ s t & = & \text { tensile reinforcing bars in RC element } \\ s U & =\text { reinforcing bars in R-UHPFRC element } \\ U & =\text { UHPFRC } \\ u & =\text { maximum or ultimate resistance; strength; resistance at peak } \\ z & =\text { vertical component of crack width } \\ & \end{array}$

\section{REFERENCES}

1. Brühwiler, E., and Denarié, E., "Rehabilitation of Concrete Structures Using Ultra-High Performance Fibre Reinforced Concrete," The Second International Symposium on Ultra High Performance Concrete (UHPC), Kassel, Germany, 2008, 902 pp.

2. Alaee, F. J., and Karihaloo, B. L., "Retrofitting of Reinforced Concrete Beams with CARDIFRC," Journal of Composites for Construction, ASCE, V. 7, No. 3, 2003, pp. 174-186.

3. Habel, K.; Denarié, E.; and Brühwiler, E., "Structural Response of Elements Combining Ultra High-Performance Fiber-Reinforced Concretes and Reinforced Concrete," Journal of Structural Engineering, ASCE, V. 132, No. 11, 2006, pp. 1793-1800.

4. Wuest, J., "Comportement structural des bétons de fibres ultra performants en traction dans des éléments composés," doctoral thesis, École Polytechnique Fédérale de Lausanne, Lausanne, Switzerland, 2007, 244 pp. (in French)

5. Oesterlee, C., "Structural Response of Reinforced UHPFRC and RC Composite Members," doctoral thesis, École Polytechnique Fédérale de Lausanne, Lausanne, Switzerland, 2010, 136 pp.

6. Kani, G. N. J., "Basic Facts Concerning Shear Failure," ACI JournAL, Proceedings V. 63, No. 6, June 1966, pp. 675-692.

7. Muttoni, A., and Schwartz, J., "Behaviour of Beams and Punching in Slabs without Shear Reinforcement," Proceedings of the IABSE Colloquium, V. 62, 1991, pp. 703-708.
8. Noshiravani, T., "Fracture Test of R-UHPFRC-RC Composite Beams Subjected to Combined Bending and Shear," PhD thesis, École Polytechnique Fédérale de Lausanne, Lausanne, Switzerland, 2011, 326 pp.

9. Vaz Rodrigues, R.; Muttoni, A.; and Fernández Ruiz, M., "Influence of Shear on Rotation Capacity of Reinforced Concrete Members without Shear Reinforcement," ACI Structural Journal, V. 107, No. 5, Sept.-Oct. 2010, pp. 516-525.

10. Leonhardt, F., and Walther, R., Schubversuche an einfeldrigen Stahlbetonbalken mit und ohne Schubbewehrung zur Ermittlung der Schubtragfähigkeit und der oberen Schubspannungsgrenze, Ernst \& Sohn, Berlin, Germany, 1962, 68 pp. (in German)

11. Collins, M. P.; Bentz, E. C.; and Sherwood, E. G., "Where is Shear Reinforcement Required? Review of Research Results and Design Procedures," ACI Structural Journal, V. 105, No. 5, Sept.-Oct. 2008, pp. 590-600.

12. Walraven, J. C., "Fundamental Analysis of Aggregate Interlock," Journal of Structural Engineering, ASCE, V. 107, No. 11, 1981, pp. 2245-2270.

13. Vecchio, F. J., and Collins, M. P., "The Modified CompressionField Theory for Reinforced Concrete Elements Subjected to Shear," ACI Journal, Proceedings V. 83, No. 2, Mar.-Apr. 1986, pp. 219-231.

14. Rossi, P.; Brühwiler, E.; Chhuy, S.; Yenq, Y.-S.; and Shah, S. P., "Fracture Properties of Concrete as Determined by Means of Wedge Splitting Tests and Tapered Double Cantilever Beam Tests," Fracture Mechanics Test Methods for Concrete: Report of Technical Committee 89-FMT Fracture Mechanics of Concrete, Test Methods, RILEM, Chapman and Hall, London, UK, 1991, pp. 87-128.

15. Mihaylov, B. I.; Bentz, E. C.; and Collins, M. P., "Behavior of Large Deep Beams Subjected to Monotonic and Reversed Cyclic Shear," ACI Structural Journal, V. 107, No. 6, Nov.-Dec. 2010, pp. 726-734.

16. Kani, M.; Huggins, M.; and Wittkopp, R., Kani on Shear in Reinforced Concrete, University of Toronto Press, Toronto, ON, Canada, 1979, 225 pp.

17. Paulay, T.; Park, R.; and Philips, M. H., "Horizontal Construction Joints in Cast-In-Place Reinforced Concrete," Shear in Reinforced Concrete, SP-42, American Concrete Institute, Farmington Hills, MI, 1974, pp. $599-616$

18. Zilch, K.; Schmidhuber, C.; and Niedermeier, R., Bauteilversuche zur Querkraftbiegung an mittels Klebearmierung verstärkten Bauteilen: [Forschungsbericht], Stuttgart: Fraunhofer-IRB-Verl., 2000, 160 pp. (in German)

19. Muttoni, A., "Punching Shear Strength of Reinforced Concrete Slabs without Transverse Reinforcement," ACI Structural Journal, V. 105, No. 4, July-Aug. 2008, pp. 440-450.

20. Stoffel, P., "Zur Beurteilung der Tragsicherheit bestehender Stahlbetonbauten," doctoral thesis, Swiss Federal Institute of Technology in Zurich, Zurich, Switzerland, 2000, 186 pp. (in German)

21. Mirzaei, Y., "Post-Punching Behavior of Reinforced Concrete Slabs," doctoral thesis, École Polytechnique Fédérale de Lausanne, Lausanne, Switzerland, 2010, $140 \mathrm{pp}$.

22. Teng, J. G.; Chen, J. F.; Smith, S. T.; and Lam, L., "Behaviour and Strength of FRP-Strenghtened RC Structures: A State-of-the-Art Review," Proceedings of the Institution of Civil Engineers Structures \& Buildings, V. 156, Institution of Civil Engineers, London, UK, 2003, pp. 51-62.

23. Muttoni, A., and Fernández Ruiz, M., "Shear Strength of Members without Transverse Reinforcement as Function of Critical Shear Crack Width," ACI Structural Journal, V. 105, No. 2, Mar.-Apr. 2008, pp. 163-172. 
NOTES: 


\section{APPENDIXES}

\section{APPENDIX A - SHEAR RESISTANCE MECHANISMS IN RC MEMBERS}

The mechanisms of shear resistance in $\mathrm{RC}$ members depend on the stresses carried by both concrete and steel.

The primary shear resistance mechanism in $\mathrm{RC}$ members is the inclined compression stress field in concrete. Strut action carries the stresses in beams with smooth rebars or in beams with deformed rebars and $a / d$ of less than approximately 2.5. The tensile force along the longitudinal reinforcement of these beams is constant. The strength of the strut depends on the concrete compressive strength and the reinforcement detailing.

Beam action resists the shear forces in members with bonded longitudinal reinforcement and $a / d>2.5$. In these members, the tension in the longitudinal reinforcement changes along the member. Upon yielding of the longitudinal rebars, the tensile force becomes constant; thus, strut action replaces beam action in carrying the shear stresses. ${ }^{9}$

The change in the tensile force is made possible by the web stresses that are carried by the shear reinforcement anchored into the longitudinal tension chord and the aggregate interlock along crack lips. ${ }^{11}$ Aggregate interlock depends on the crack width, compressive stresses across the crack, shear displacement, and concrete quality. ${ }^{12,13}$ The vertical and longitudinal reinforcement crossing the cracks control their opening and enhance aggregate interlock. The roughness of the crack lips depends on the strength of concrete and the size and strength of its aggregates. ${ }^{13,14}$ Cracks that pass through the aggregates are smooth and reduce aggregate interlock. This is often the case of highstrength concretes or mixes with low-strength aggregates.

Beam versus strut action in RC beams with ribbed and smooth rebars are shown in Fig. B-1. ${ }^{10 \text {, }}$ ${ }^{15}$ Aggregate interlock (AI) and dowel action (DA) of the rebars at flexural cracks resist the bending of the concrete segments between the cracks that is caused by the bond stresses between concrete and rebars along the base of the segment. ${ }^{16}$ A similar phenomenon occurs between the flexure-shear cracks in an $\mathrm{RC}$ element with glued tensile steel plates, except that dowel action (mainly the 
contribution of the rebars bending at a crack) is replaced with the out-of-plane bending of the steel plates. $^{17,18}$

a) Beam action
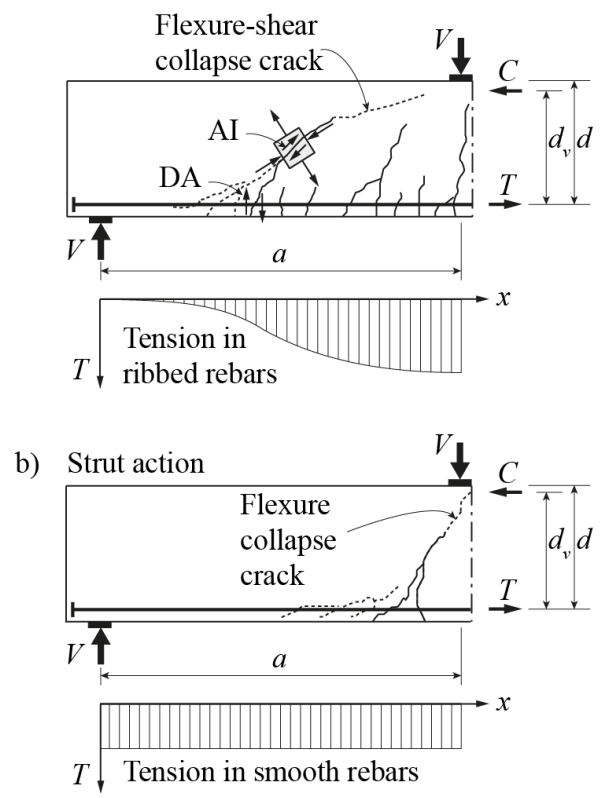

Fig. A-1 - (a) Beam versus (b) strut action in RC beams subjected to point loads. ${ }^{10,15}$

The localization of web deformations at a flexure-shear crack and the interference of this crack with the compression stress field in the web cause the flexure-shear failure of RC members. ${ }^{7}$ Flexure-shear failure occurs along the collapse or so-called critical crack and determines the member resistance and rotation capacity. ${ }^{7,19,20}$ Following a flexure-shear failure, the dowel action of the longitudinal rebars embedded in concrete and the membrane action of the tensile reinforcement continue to provide residual resistance. ${ }^{21}$ 
Appendix B - UHPFRC mix HIFCOM $13^{5}$

Table B-1 - Mix design $(1 \mathrm{~kg} / \mathrm{m3}=0.062 \mathrm{lbm} / \mathrm{ft} 3$ and $1 \mathrm{~mm}=0.0394 \mathrm{in})$.

\begin{tabular}{|l|l|}
\hline CEM III B cement & $1277.4 \mathrm{~kg} / \mathrm{m} 3$ \\
\hline silica fume & $95.8 \mathrm{~kg} / \mathrm{m} 3$ \\
\hline sand & $664.6 \mathrm{~kg} / \mathrm{m} 3$ \\
\hline $\begin{array}{l}\text { Steel fibers } \\
\text { length }=13 \mathrm{~mm} ; \\
\text { Diameter }=0.16 \mathrm{~mm}\end{array}$ & $\begin{array}{l}235.5 \mathrm{~kg} / \mathrm{m} 3 \\
\text { that is } 3 \% \text { by volume }\end{array}$ \\
\hline Superplasticiser & $42.3 \mathrm{~kg} / \mathrm{m} 3$ \\
\hline Water & $0.155 \mathrm{~kg} / \mathrm{m} 3$ \\
\hline
\end{tabular}
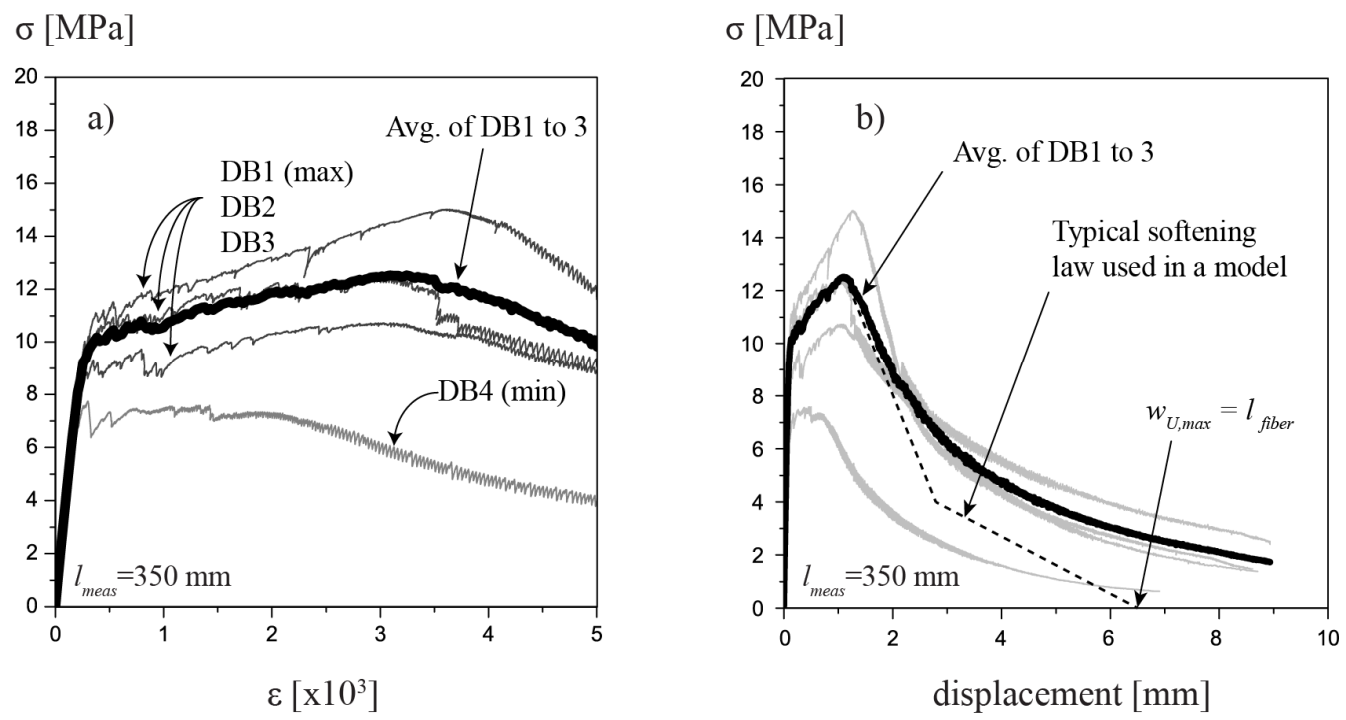

Fig. B-1 - Tensile behavior of plain UHPFRC from horizontally cast dog-bone specimens (1 $\mathrm{MPa}=145.0 \mathrm{psi} ; 1 \mathrm{~mm}=\mathbf{0 . 0 3 9 4}$ in). 


\section{Appendix C - Results of tensile tests on steel rebars}
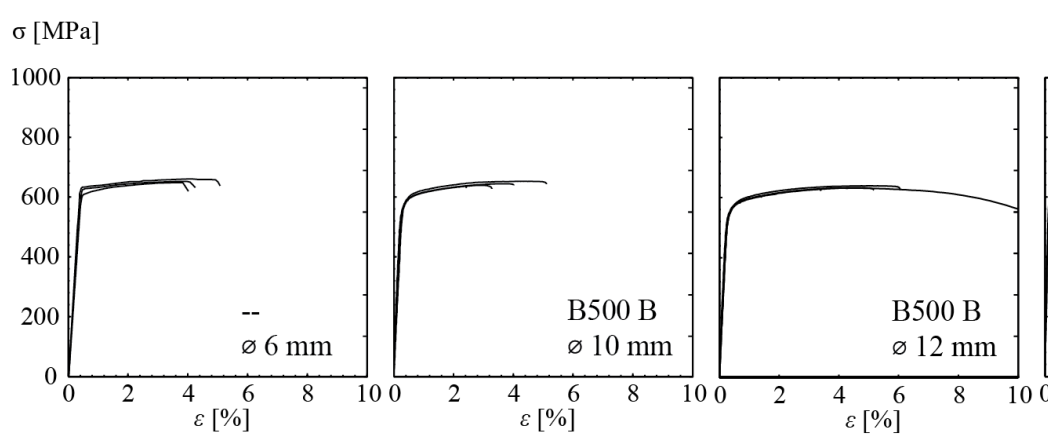

(ksi)

$\sigma[\mathrm{MPa}]$
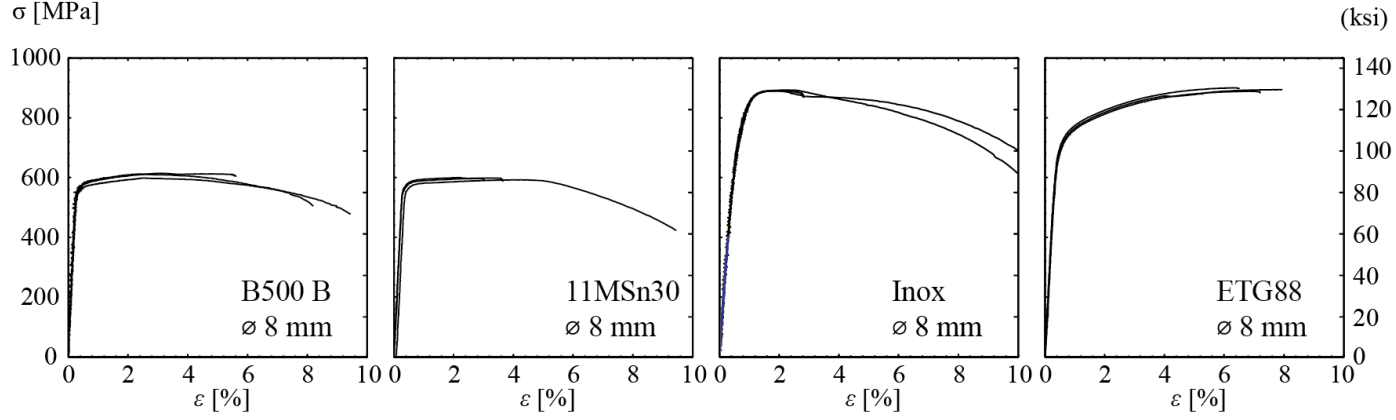

Fig. C-1 - Stress-strain curves of steel rebars. 